\title{
Insight into the order-disorder transition of irradiated pyrochlore solid solutions as potential nuclear waste forms
}

\author{
SHIRLEY CHANG ${ }^{1}$, GORDON J THOROGOOD ${ }^{2}$, MAX
} AVDEEV $^{2}$, FELIX BRANDT ${ }^{3}$, DIRK BOSBACH ${ }^{4}$, MIHAIL IONESCU $^{5}$, DAVID SIMEONE ${ }^{6}$ AND SARAH C FINKELDEI $^{1}$

${ }^{1}$ University of California, Irvine

${ }^{2}$ ANSTO

${ }^{3}$ Forschungszentrum Jülich, Germany

${ }^{4}$ Forschungszentrum Jülich GmbH

${ }^{5}$ Australian Nuclear Science and Technology Organization

${ }^{6}$ Structures, Properties and Modeling of Solids Laboratory

Presenting Author: shirlc6@uci.edu

Pyrochlores $\left(\mathrm{A}_{2} \mathrm{~B}_{2} \mathrm{O}_{7}\right)$, a common mineral that can uptake large quantities of actinides, are studied as potential nuclear waste forms to immobilize radionuclides. Many have studied pyrochlore solid solutions where different cations on the A or B site are mixed to imitate waste loading of e.g. Pu within the pyrochlore structure. As a response to irradiation or selfirradiation, zirconate $(\mathrm{B}=\mathrm{Zr})$ pyrochlores are known to undergo an order/disorder phase transition into a disordered defect fluorite structure while titanate $(\mathrm{B}=\mathrm{Ti})$ pyrochlores become amorphous, however the dominating factor towards phase transition of each is unclear in a solid solution. To gain insight into order-disorder processes, the stress and strain of $\mathrm{Nd}_{2} \mathrm{Zr}_{2} \mathrm{O}_{7}$ and $\mathrm{Er}_{2} \mathrm{Ti}_{2} \mathrm{O}_{7}$ endmembers and a $(\mathrm{ErNd})_{2}(\mathrm{TiZr})_{2} \mathrm{O}_{7}$ solid solution were examined. Prior and upon irradiation $\mathrm{Nd}_{2} \mathrm{Zr}_{2} \mathrm{O}_{7}$ and $\mathrm{Er}_{2} \mathrm{Ti}_{2} \mathrm{O}_{7}$ both showed no strain. With regards to $(\mathrm{ErNd})_{2}(\mathrm{TiZr})_{2} \mathrm{O}_{7}$, it appears that the synthesis method employed was not sufficient to achieve a 50:50 ratio of $\mathrm{A}$ and $\mathrm{B}$ cations according to the diffraction results. However, the solid solution contained strain while $\mathrm{Nd}_{2} \mathrm{Zr}_{2} \mathrm{O}_{7}$ and $\mathrm{Er}_{2} \mathrm{Ti}_{2} \mathrm{O}_{7}$ was strain free. Further synthesis approaches of $(\mathrm{ErNd})_{2}(\mathrm{TiZr})_{2} \mathrm{O}_{7}$ solid solution members are under way to understand the irradiation response of such mixed A and B site pyrochlores. 